ISSN: 2578-0263

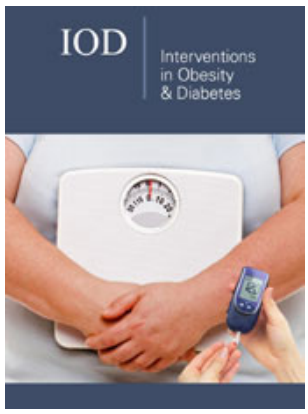

*Corresponding author: Carmine Finelli, Department of Internal Medicine, Ospedale Cav R Apicella-ASL Napoli 3 Sud, Via di Massa, 80040 Pollena (Napoli), Italy

Submission: 望 January 18, 2021

Published: 監 February 01, 2021

Volume 4 - Issue 5

How to cite this article: Carmine Finelli. A Possible Correlation between Obesity, Covid-19 and Vitamin D. Interventions Obes Diabetes 4(5). IOD.000599. 2021. DOI: 10.31031/IOD.2021.04.000599

Copyright@ Carmine Finelli. This article is distributed under the terms of the Creative Commons Attribution 4.0 International License, which permits unrestricted use and redistribution provided that the original author and source are credited.

\section{A Possible Correlation between Obesity, Covid-19 and Vitamin D}

\author{
Carmine Finelli*
}

Department of Internal Medicine, Covid Hospital Boscotrecase, Italy

\section{Opinion}

Obesity is correlated with significant human and social costs, an intransigent pandemic epidemic that is rising worldwide. At the same time, high obesity rates are known to decrease defense against pathogens. Around the same moment, high prevalence of obesity, considered to decrease defense against pathogens [1], are seen in patients with COVID-19 and particularly in those with metabolic syndrome associated with obesity. Even so, the correlation between decreased obesity and inadequate immune function and infection propensity presents significant issues about the likelihood of greater viral infectivity in this population [2]. The incidence of COVID-19 disease could also identify opportunities to body mass index [3]. A possible mechanism developed to describe this result is that elevated adiposity could compromise the pulmonary cell membrane in which a disordered loop of local inflammation, immune responses, and secondary injury is set up by the virus that tends to interfere with the host in this setting [4]. An even more significant problem is that obesity may entail a deficiency/insufficiency of vitamin $\mathrm{D}[2,5]$ thereby reducing the ability of the obese patients to reduce the risk of viral infections as effectively as lean people. Vitamin D deficiency can, in its own right, also generate or encourage states of obesity, diabetes, and cardiovascular disease [6]. Understandably, patients suffering from low vitamin D, such as those who are obese, tend to have at elevated risk for COVID-19 [7]. Therefore, to mitigate the effects of misery as a result of COVID-19, and especially among the population at risk of obesity, it can be suggested that a position for the prevention of obesity [8], weight loss, plus vitamin D supplementation as required, should not be ignored before a vaccine or some sort of therapy is arisen. Many studies indicate that, due to the effect of obesity on prolonged viral shedding, lockdown in obese patients should probably be prolonged than is suggested for individuals of average weight. The world is obviously in the middle between an obesity epidemic and an unforeseen viral pandemic, it is necessary therefore to encourage researchers and clinicians to urgently explore ways to either avoid or reduce the effect of obesity other than vaccination and isolation, as well as COVID-19 and its ability to spread quickly [9].

Another, it is necessary encourage both public health professionals and political leaders to still do everything that they can across appropriate public health initiatives and advertisements to concentrate on efforts to minimize obesity as well as the risk of COVID-19 infections, frequently related to obesity. Within that context, and in regards to investing health initiatives, this could include informing the public on the importance of vitamin D in lowering the risk of respiratory tract infections and growing the resistance to infections, as well as having a positive effect on those who are obese and who are at increased risk of COVID-19. For now, it seems rational to presume that vitamin D supplementation or usage could provide a secure method of positively affecting obesity and COVID-19 infection rates, in accordance to weight loss strategies, where possible. In addition, measures to encourage optimum immune function by weight reduction in obese people can also be beneficial. The predicted advantages of this strategy might just be that obese adults who maintain a good or ideal weight could have less risk of COVID-19 infections, and could recover more easily, need less intensive hospitalization, and be more effective and more freely able to engage in outdoor activity within the prescribed safety limits [10]. In conclusion, educational programs, nutritionists and other physicians could be able to expand this knowledge to social media health websites 
and forums used by adults for specific nutrients containing vitamin $\mathrm{D}$, thereby guaranteeing that what individuals have been related to in this manner is based on science and provides for particularly viable secure, inexpensive solutions and activities, particularly during the winter months.

\section{References}

1. Finelli C (2020) Obesity and immunotherapy: The surprisingly positive association! Immunotherapy 12(8): 541-544.

2. Kara M, Ekiz T, Ricci V, Kara Ö, Chang KV, et al. (2020) 'Scientific Strabismus' or two related pandemics: coronavirus disease and vitamin D deficiency. Br J Nutr 124(7): 736-741.

3. Finelli C (2020) Obesity, COVID-19 and immunotherapy: The complex relationship! Immunotherapy 12(15): 1105-1109.

4. Philip KEJ, Lonergan B, Cumella A, Douglas JF, Laffan M, et al. (2020) COVID-19 related concerns of people with long-term respiratory conditions: A qualitative study. BMC Pulm Med 20(1): 319.
5. Mohan M, Cherian JJ, Sharma A (2020) Exploring links between vitamin D deficiency and COVID-19. PLoS Pathog 16(9): e1008874.

6. de Lucena TMC, da Silva Santos AF, de Lima BR, de Albuquerque Borborema ME, de Azevêdo Silva J (2020) Mechanism of inflammatory response in associated comorbidities in COVID-19. Diabetes Metab Syndr 14(4): 597-600.

7. Pinzon RT, Angela, Pradana AW (2020) Vitamin D deficiency among patients with COVID-19: case series and recent literature review. Trop Med Health 48(1): 102.

8. Zhao X, Gang X, He G, Li Z, Lv Y, et al. (2020) Obesity increases the severity and mortality of influenza and COVID-19: A systematic review and meta-analysis. Front Endocrinol (Lausanne) 11: 595109.

9. Lockhart SM, O Rahilly S (2020) When two pandemics meet: Why is obesity associated with increased COVID-19 mortality? Med (N Y) 1(1): 33-42.

10. Kim SY, Yoo DM, Min C, Wee JH, Kim JH, et al. (2020) Analysis of mortality and morbidity in COVID-19 patients with obesity using clinical epidemiological data from the Korean center for disease control \& prevention. Int J Environ Res Public Health 17(24): 9336. 